\title{
A NUMERICAL STUDY OF OSCILLATING SUB-BOUNDARY LAYER VORTEX GENERATORS APPLICATION
}

NUR FARAIHAN BINTI ZULKEFLI

UNIVERSITI SAINS MALAYSIA

2011 
Master of Science

\section{UNIVERSITI SAINS MALAYSIA}

June 2011 


\section{ACKNOWLEDGEMENT}

Firstly, Alhamdulillah, praise to Allah S.W.T and his prophet Nabi Muhammad S.A.W for enabling me to finish my master project which I have been blessed with good health and peaceful mind while doing this project. This master project was conducted under my supervisor, Dr. Kamarul Arifin bin Ahmad in the School of Aerospace Engineering. I am very grateful to him for his patience and constructive comments that enriched this research project. Time and efforts by him have been a great contribution during the preparations of this thesis. To my friends, M. Zubair, H. Fauzi and others, thanks a lot for their valuables comments, support and sharing their time and knowledge in this research project.

I am gratefully acknowledging the assistance of everybody who helped indirectly and directly in the execution of this research, especially technicians and staffs at Computer Aided Education Laboratory. I also want to give special dedication to my mother and my beloved family members who give their supports and motivations during my progressing of this project. Last but not least for those who contribute, again thank you very much. 


\section{TABLE OF CONTENTS}

Acknowledgement

Table of Contents iii

List of Tables $\quad$ viii

List of Figures $\quad$ ix

Nomenclature $\quad$ xiv

$\begin{array}{ll}\text { Abstract } & \text { xvii }\end{array}$

$\begin{array}{lll}\text { Abstrak } & \text { xviii }\end{array}$

\section{CHAPTER 1-INTRODUCTION}

1.1 Overview 1

1.2 Investigation Technique 2

1.3 Numerical Methods 3

1.4 Problem Statement 4

1.5 Aims and Objectives 6

1.6 Thesis Organisation 6

\section{CHAPTER 2- LITERATURE REVIEW}

2.1 Flow Separation Control 7

2.2 Types of Active Vortex generators 8

$\begin{array}{llr}\text { 2.2.1 } & \text { Air Jets } & 8\end{array}$

2.2.1(a) Synthetic Jets $\quad 8$

2.2.1(b) Pulsed Jets 15 
$\begin{array}{ll}\text { 2.2.2 Structural Vibrations } & 18\end{array}$

$\begin{array}{lll}2.3 & \text { Numerical setting and configurations } & 23\end{array}$

$\begin{array}{lll}\text { 2.3.1 Two-dimensional (2D) simulations } & 23\end{array}$

2.3.1(a) Structured Mesh 23

2.3.1(b) Hybrid Mesh 25

$\begin{array}{lll}\text { 2.3.2 Three-dimensional(3D) simulations } & 27\end{array}$

$\begin{array}{ll}\text { 2.3.2(a) Structured Mesh } & 27\end{array}$

2.3.2(b) Unstructured Mesh 28

2.4 Solver Setting $\quad 29$

$\begin{array}{lll}2.4 .1 & \text { RANS approach } & 29\end{array}$

$\begin{array}{lll}\text { 2.4.2 LES approach } & 31\end{array}$

2.4.3 Hybrid URANS/LES approach 32

$\begin{array}{lll}\text { 2.4.4 DNS approach } & 33\end{array}$

$\begin{array}{lll}2.5 & \text { Summary } & 33\end{array}$

CHAPTER 3-METHODOLOGY

3.1 Numerical Methods $\quad 35$

$\begin{array}{ll}\text { 3.1.1 Governing equations } & 35\end{array}$

3.1.2 Mesh Motion and Updates 36

3.1.3 Turbulence Modelling 39

3.2 SBVG and Computational Models $\quad 40$

$\begin{array}{lll}3.2 .1 & \text { Flat plate } & 40\end{array}$

3.2.2 Eagle 150B wing's flap 42 
3.2.3 SBVG Oscillation motion domain 45

3.2.4 Measurement planes and profiles 46

$\begin{array}{lll}3.3 & \text { Grid System } & 48\end{array}$

3.3.1 Meshing technique 48

$\begin{array}{lll}\text { 3.3.2 Boundary condition } & 48\end{array}$

3.3.2(a) Velocity inlet $\quad 48$

3.3.2(b) Interface $\quad 49$

3.3.2(c) Pressure outlet 49

3.3.2(d) Wall boundary $\quad 49$

$\begin{array}{ll}3.3 .2(e) \quad \text { Symmetry } & 50\end{array}$

$\begin{array}{lll}\text { 3.3.3 Simulations procedures } & 50\end{array}$

\section{CHAPTER 4-RESULT AND DISCUSSIONS}

4.1 Static Vortex Generators 53

4.1.1 Comparisons with experimental data 54

4.1.2 Streamwise velocity contours 56

$\begin{array}{lll}\text { 4.1.3 Turbulent kinetic energy } & 58\end{array}$

$\begin{array}{lll}\text { 4.1.4 Streamwise vorticity contours } & 60\end{array}$

4.1.5 Comparisons between Different Incident Angle ( $\beta) \quad 62$

4.1.6 Skin Friction Coefficient $\left(\mathrm{C}_{\mathrm{f}}\right) \quad 65$

4.1.7 Comparisons between Co-rotating(Co) and Counter- 69 Rotating(Co-R)

4.2 Oscillating Vortex Generators 71 
$\begin{array}{lll}\text { 4.2.1 Parametric study } & 71\end{array}$

$\begin{array}{lll}\text { 4.2.1(a) Time-dependency solution } & 72\end{array}$

4.2.1(b) Mesh-dependency solution $\quad 74$

$\begin{array}{lll}\text { 4.2.2 } & \text { Formation of vortex } & 76\end{array}$

$\begin{array}{lll}\text { 4.2.3 Streamwise vorticity contours } & 78\end{array}$

4.2.4 Comparisons between Static and Oscillating SBVG 82

4.2.5 Skin Friction Coefficient $\left(\mathrm{C}_{\mathrm{f}}\right) \quad 86$

$\begin{array}{lll}4.3 & \text { Summary } & 88\end{array}$

\section{CHAPTER 5-APPLICATION OF OSCILLATING SBVG}

$\begin{array}{llr}5.1 & \text { Static SBVG } & 89\end{array}$

5.1.1 Mesh dependency $\quad 89$

5.1.2 Effect of Static Flow Control 90

$\begin{array}{lll}\text { 5.1.3 Velocity contour } & 92\end{array}$

$\begin{array}{lll}\text { 5.1.4 Velocity profiles } & 93\end{array}$

$\begin{array}{lll}5.2 & \text { Oscillating SBVG } & 94\end{array}$

5.2.1 Effect of Oscillating SBVG Flow Control 94

5.2.2 Comparison between Static and Oscillating SBVG 97

5.2.3 Effects of Reynolds number 99

5.2.4 Effects of Reynolds number for Lift and Drag 100 Coefficient

$\begin{array}{lll}5.3 & \text { Summary } & 102\end{array}$ 


\section{CHAPTER 6- CONCLUSION AND RECOMMENDATION}

$\begin{array}{lll}\text { 6.1 Oscillating SBVG on a Flat Plate } & 103\end{array}$

6.2 Oscillating SBVG on a Eagle 150B wing's Flap 104

$\begin{array}{lll}6.3 & \text { Future Works } & 104\end{array}$

REFERENCES 106

PUBLICATIONS 114 


\section{LIST OF TABLES}

Table 4.1 SBVG Oscillation properties and timeline for flat plate simulations $\quad 82$

Table 5.1 Mesh dependency solution for Eagle 150B wing's flap $\quad 89$

Table 5.2 Eagle 150B wing's flap configurations 90

Table 5.3 SBVG Oscillation properties and timeline for Eagle 150B wing's 95 flap

Table 5.4 Reynolds number properties

99 


\section{LIST OF FIGURES}

Figure 2.1 (a)Diagram of synthetic jets on NACA0015;

(b)Mesh close to jet [31]

Figure 2.2 (a)Mesh around the airfoil with co-flow slot;

(b)Baseline airfoil NACA 2415 with co-flow jet slot[34]

Figure 2.3 Data for an unexcited and excited flow[6]

Figure $2.4 \quad$ (a)Diagram of a Synthetic Jet Actuator (SJA) in crossflow;

(b)Numerical grids of SJA[38]

Figure 2.5 Temporal Fourier analysis with variation of oscillation amplitude for $\omega=17$ and $\mathrm{d}=0.225$ for (a)flat plate; (b)airfoil[40]

Figure 2.6 (a) JaVA Actuator [42]; (b) Multi-block grid [43]

Figure 2.7 Schematic of pulsed vortex generators jet flow control on the flap surface [51]

Figure 2.8 Grid features for numerical simulations [50]

Figure 2.9 Grids in computational domain on the (a) flat plate [51];

(b) upper surface of the airfoil and in X-Z plane [52]

Figure 2.10 (a) Trailing edge deflector (TED); (b) vortex generator [56]

Figure 2.11 Computational mesh that represents the clean HQ17 airfoil as well as a configuration of airfoil and flap [57]

Figure 2.12 (a)Three zone overset grid used for moving flap computation;

(b) Enlarged view of the overset grid near the trailing edge [58]

Figure 2.13 (a) Schematic side view of a single DBD actuator with probes [60];

(b) Computed electric contours and streamlines of the electrodes (right) $[63,64]$

Figure 2.14 Unstructured computational grids with details of the slot region [37]

Figure 3.1 Computational domains of the vortex generator and boundary condition (a) Side view; (b) Geometrical design of SBVG 
Figure 3.2 The geometry of (a) Co-rotating(Co) devices and (b) Counterrotating (Co-R) devices

Figure 3.3 SBVG image in hybrid mesh geometry

Figure 3.4 Computational domains of the Eagle 150B wing's flap and boundary condition (a) Side view; (b) Geometrical design of SBVG on Eagle 150B wing's flap

Figure 3.5 (a) Mesh domain for Eagle 150B airfoil in and boundary condition;

(b) Zoom in view of Eagle 150B airfoil mesh

Figure 3.6 The image of the structured and unstructured mesh of SBVG applied on Eagle 150B wing's flap

Figure 3.7 SBVG pitching motion direction on (a) flat plate and (b) Eagle 150B wing's flap

Figure 3.8 Downstream plane of SBVG trailing edge for (a) flat plate (b) Eagle 150B wing's flap

Figure 3.9 Spanwise locations for flow profile property analysis

Figure 3.10 Process to simulate the unsteady flows

Figure 3.11 Simple harmonic motion between $18^{\circ}$ and $-18^{0}$

Figure 3.12 The uniform sinusoidal motion

Figure 4.1 Crossflow velocity vector for both (a) experiment from McEwan [85] and (b) simulation from CFD at location 2c

Figure 4.2 Crossflow velocity vector for both (a) experiment from McEwan [85] and (b) simulation from CFD at location 4c

Figure 4.3 Normalized streamwise velocity contour at plane X1

Figure 4.4 Normalized streamwise velocity contour at plane X2

Figure 4.5 Normalized streamwise velocity contour at plane X3

Figure 4.6 Turbulent kinetic energy contour at plane X1

Figure 4.7 Turbulent kinetic energy contour at plane X2 
$\begin{array}{lll}\text { Figure } 4.8 & \text { Turbulent kinetic energy contour at plane X3 }\end{array}$

Figure 4.9 Normalized streamwise vorticity contour at location X1 plane 61

Figure 4.10 Normalized streamwise vorticity contour at location X2 plane 61

Figure 4.11 Normalized streamwise vorticity contour at location X3 plane 62

Figure 4.12 Normalized streamwise velocity profiles at spanwise location (a) 65 $\mathrm{P} 2=-\mathrm{h}$, (b) $\mathrm{P} 1=-0.5 \mathrm{~h}$, (c) $\mathrm{Z} 0=0 \mathrm{~h}$, (d) $\mathrm{S} 1=0.5 \mathrm{~h}$ and (e) $\mathrm{S} 2=\mathrm{h}$

Figure 4.13 Skin friction coefficient at spanwise location at (a)X1,(b) X2and (c) X3

Figure 4.14 Normalized streamwise velocity for static $18^{0}$ at location (a) X1,(b) 68 $\mathrm{X} 2$ and (c) X3

Figure 4.15 Normalized streamwise velocity profiles at $18^{0}$ for Co-rotating(Co) 71 and Counter-Rotating (Co-R) at spanwise locations (a) $\mathrm{P} 2=-\mathrm{h}$, (b) $\mathrm{Z} 0=0 \mathrm{~h}$, (c) $\mathrm{S} 2=\mathrm{h}$

$\begin{array}{lll}\text { Figure 4.16 Time step dependencies check with x-velocity profiles } & 73\end{array}$

$\begin{array}{lll}\text { Figure 4.17 Time step dependencies check with y-velocity profiles } & 73\end{array}$

Figure 4.18 Time step dependencies check with z-velocity profiles 74

Figure 4.19 Mesh dependency check with x-velocity profiles 75

Figure 4.20 Mesh dependency check with y-velocity profiles 75

Figure 4.21 Mesh dependency check with z-velocity profiles 76

Figure 4.22 Normalized streamwise velocity contour at $\bar{T}=0$

$\begin{array}{lll}\text { Figure 4.23 Normalized streamwise velocity contour at } \bar{T}=4 & 77\end{array}$

Figure 4.24 Normalzied streamwise velocity contour at $\bar{T}=5.625$

$\begin{array}{lll}\text { Figure } 4.25 \text { Normalized streamwise velocity contour at } \bar{T}=5.75 & 78\end{array}$

Figure 4.26 Normalized streamwise vorticity contour at $\bar{T}=0 \quad 79$

Figure 4.27 Normalized streamwise vorticity contour at $\bar{T}=4 \quad 80$ 
Figure 4.28 Normalized streamwise vorticity contour at $\bar{T}=5.6248$

Figure 4.29 Normalized streamwise vorticity contour at $\bar{T}=5.75$

Figure 4.30 Normalized streamwise vorticity contour at $\bar{T}=9.75$

Figure 4.31 Normalized streamwise vorticity contour at $\bar{T}=20$

Figure 4.32 Time averaged velocity profiles in spanwise locations at (a) $\mathrm{P} 2=-\mathrm{h}, \quad 85$ (b)P1=-0.5h, (c)Z0=0h, (d)S1=0.5h and (e) S2=h

Figure 4.33 Time-averaged skin friction coefficient at streamwise location (a) 87 X1 (b) X2 and (c) X3

Figure 5.1 Lift coefficient at different angle of attack $\quad 91$

Figure 5.2 Drag coefficient at different angle of attack $\quad 91$

Figure 5.3 Lift-to-Drag ratio at different angle of attack 92

Figure 5.4 Velocity contour for Eagle 150B wing's flap for (a) Case II and (b) 93 Case III

Figure 5.5 Velocity plots between Cases II and Cases III at spanwise location $\mathrm{Z} 0$

Figure 5.6 Instantaneous streamwise velocity contours for Cases A at plane Z0 96

Figure 5.7 Instantaneous streamwise velocity contours for Cases B at plane Z0 96

Figure 5.8 Instantaneous streamwise velocity contours for Cases C at plane Z0 97

Figure 5.9 Instantaneous streamwise velocity contours for Cases D at plane Z0 97

Figure 5.10 Lift coefficient for static and oscillating SBVG at different $\quad 98$ frequencies

Figure 5.11 Drag coefficient for static and oscillating SBVG at different 98 frequencies

Figure 5.12 Lift-to-Drag ratio for static and oscillating SBVG at different frequencies

Figure 5.13 Instantaneous streamwise velocity contour for Case D1 at plane Z0 100 
Figure 5.14 Instantaneous streamwise velocity contour for Case D2 at plane Z0 100

Figure 5.15 Lift coefficient at different Reynolds number 101

Figure 5.16 Drag coefficient at different Reynolds number 101

Figure 5.17 Lift-to-Drag ratio at different Reynolds number 102 


\section{NOMENCLATURE}

\section{Roman symbols}
A
amplitude
C
airfoil chord
c
vortex generator's length
$\mathrm{C}_{\mathrm{D}}$
coefficient of drag
$\mathrm{C}_{\mathrm{L}}$
coefficient of lift
$\mathrm{C}_{\text {Lmax }}$
Maximum lift coefficeint
$\mathrm{C}_{\mathrm{f}}$
coefficient of skin friction
$C_{\mu}$
coefficient of momentum
D
distance between two devices
f
natural frequency
$F^{+}$
reduced frequency
$\mathrm{p}$
pressure
$\operatorname{Re}$
Reynolds number
S
spacing between two pair of devices
$\mathrm{t}$
time
$\mathrm{T}$
time for one cycle
$\bar{T}$
number of cycles ratio
$u_{\infty}$
freestream velocity
$-\overline{u v},-\overline{u w}$
time-averaged Reynolds shear stress components 


\section{Greek symbols}

$\begin{array}{ll}\alpha & \text { angle of attack } \\ \beta & \text { vortex generator incident angle } \\ \delta & \text { boundary layer thickness } \\ \partial & \text { partial differential equation } \\ \partial V & \text { boundary of control volume } \\ \mathrm{k} & \text { turbulent kinetic energy } \\ \varepsilon & \text { dissipation rate of k } \\ \rho & \text { fluid density } \\ \tau & \text { shear stress } \\ \tau_{\omega} & \text { wall shear stress } \\ \phi & \text { general scalar } \\ \omega & \text { specific rate of dissipation of k }\end{array}$

\section{Abbreviations}

AFC

AJVG

CFD

DBD

DNS

LES

L/D

LSB
Active flow control

Air-jet vortex generator

Computational Fluid Dynamics

Dielectric Barrier Discharge

Direct Numerical Simulation

Large Eddy Simulation

lift-to-drag ratio

Laminar Separation Bubble 
MEMS

NACA

RANS

SBVG

sec

SST

TED

UDF

URANS

VG

ZNMF
Micro-electromechanical system

(U.S) National Advisory Committee for Aeronautics

Reynold-averaged Navier Stokes

sub-boundary layer vortex generator

second

shear stress transport model

trailing edge deflector

User-defined function

Unsteady Reynold-averaged Navier Stokes

vortex generator

zero-net-mass-flux 


\title{
A NUMERICAL STUDY OF OSCILLATING SUB-BOUNDARY LAYER VORTEX GENERATORS APPLICATION
}

\begin{abstract}
A numerical simulation for oscillating sub-boundary layer vortex generator (SBVG) with Co-rotating (Co) and Counter-Rotating (Co-R) configurations was carried out. The device was attached and tested on a flat plate with zero- pressure gradient condition. This three-dimensional (3D) simulation adopted a fully turbulent flow, having a Reynolds number of $1 \times 10^{6}$. The Reynolds-averaged Navier-Stokes (RANS) equations with the SST k- $\omega$ turbulence model were used to predict the flow field which employed hybrid mesh. The SBVG was oscillated in a sinusoidal motion between $18^{0}$ and $-18^{0}$. The results show that the profile for Counter-Rotating (Co-R) SBVG was more dominant due to its strong vortices compared to co-rotating.

A two-element high-lift configuration with oscillating SBVG attached at the leading edge of the flap was simulated based on the RANS equations with SST k- $\omega$ turbulence model. Four different reduced frequencies with Reynolds numbers of $8.4 \times 10^{5}$ were studied. The effect of oscillating SBVG motion in the range of $18^{0}$ and $-18^{0}$ on aerodynamic coefficients was investigated. The results show that the vortex formation on the flap surface was almost invisible when the reduced frequency was increased. The oscillating SBVGs produce higher lift coefficient and drag coefficient, however the liftto-drag ratio was almost the same as the static SBVG.
\end{abstract}




\title{
SEBUAH KAJIAN BERANGKA MENGENAI APLIKASI AYUNAN PENJANA VORTEK DI DALAM LAPISAN SUB-SEMPADAN
}

\begin{abstract}
ABSTRAK
Sebuah kajian mengenai ayunan sub-sempadan penjana vortek (SBVG) disimulasikan pada kedudukan sama sudut (Co) dan sudut bertentangan (Co-R) telah dijalankan. Peranti vortek dipasang dan diuji pada permukaan rata dengan kecenderungan sifar. Aliran olakan ini disimulasi pada tiga dimensi (3D) dengan bilangan Reynolds $1 \times 10^{6}$. Aliran medan di dalam jejaring hidribdiramalkan dengan menggunakan persamaaan Reynolds-average Navier-Stokes (RANS) dengan model olakan SST k- $\omega$. SBVG ini berayun dalam gerakan bentuk sinul di antara sudut $-18^{0}$ hingga $18^{0}$. Kajian menunjukkan bahawa garisan susuk untuk SBVG yang bertentangan boleh menyebarkan dengan lebih jauh aliran pusaran jika dibandingkan dengan sudut yang sama.

Kerajang udara dengan dua elemen dipasangkan dengan ayunan SBVG diletakkan pada permukaan sayap kibas dan disimulasikan berdasarkan persamaan RANS dengan model olakan SST k- $\omega$. Empat jenis frekuensi penurunan dikaji dengan bilangan Reynolds $8.4 \times 10^{5}$. Ayunan SBVG digerakkan di antara $18^{0}$ hingga $-18^{0}$ untuk mengkaji pekali aerodinamik. Pembentukan pusaran pada permukaan sayap kibas hampir tidak kelihatan apabila frekuensi penurunan dikurangkan. Keputusan menunjukkan pekali daya angkat dan daya seretan meningkat bagi ayunan SBVG, tetapi menghasilkan keputusan yang hampir sama dengan SBVG pegun bagi nisbah diantara daya angkat terhadap daya seretan.
\end{abstract}




\section{CHAPTER 1}

\section{INTRODUCTION}

\subsection{Overview}

Nowadays, flow control technique is the most popular research subject in the field of aerodynamics. This technology has the potential for improving the aircraft fuel consumption. It gains tremendous interest and application since 1960's in both military and civilian sectors [1].

The manipulation of flow behavior in the boundary layer is the main technique in delaying transition from laminar to turbulent. Suppression of turbulence and prevention or postponement of separation, significantly reduce the pressure drag, enhance the lift, noise suppression and improves the performance of the aircraft. A simple and inexpensive small device is easy to build and has minimum problem. Initially, an array of small and passive devices is installed on the wall surface, especially on wing surfaces or high-lift airfoil such as flap. This small device is known as vortex generator. Although, these devices are simple, rugged and relatively low cost, there are also disadvantages such in multiple flight condition which passive devices cannot be controlled for landing/take-off and in the maneuvering flight envelope. Their passive configurations also add parasitic drag, in situation where control is not needed for steady cruise condition.

Active flow control is a new approach to control boundary layer separation. This flow control devices required energy expenditure to manipulate fluid flow. One of the best active vortex generators is the vortex generator jets. Wallis is the first person who employed air-jet vortex generator (AJVG) [2]. The air-jets can be steady or pulse jets. Most of the vortex generator jets are applied to high speed flow and to 
control shock-induced separation. For the vortex generator jets, the strength of the longitudinal vortices is controlled by the jet speed. Furthermore, a new and interesting approach is the reactive flow controls. One of the reactive control devices is the micro-electromechanical systems (MEMS). This technology used a microsensor which send signal to flow control devices to react according to flow conditions. Reactive control is used to manipulate the coherent structure in turbulent shear flow and usually applied on surface perturbations, or dynamically to near-wall coherent events.

In the present study, simulations of passive and active flow control devices are carried out. The objective of this project is to investigate the performance of active vortex generator on flat plate and flap surface of Eagle 150B airfoil. The oscillation is governed by harmonic motion controlled by the reduced frequency.

\subsection{Investigation Technique}

Most of the works related to the flow control has been carried out using experimental approach. Experiments develop the fundamental principles of flow of boundary layer. Experiments are reliable method to investigate and provide accuracy results. However, these investigations are very expensive and also needs to be repeated in order to get accurate results.

Nowadays, Computational Fluid Dynamic (CFD) is one of the alternative ways to assist the experimental investigations. There are three elements in CFD such as pre-processing, solver and post-processing. Pre-processing is the definition and modelling of the geometry region. The computational domain will be split into a smaller number using grid generation and boundary conditions are specified to define the domain boundary. Solver is where the flow mathematical equations are 
solved. Finally, in post-processor, the result can be visualized. CFD plays an important role in the study of fluid dynamic problems as it can give fast and inexpensive results thereby save cost and time. But, however, the reliability of CFD output is questionable, if physics involved in the fluid flow phenomenon like turbulence, material properties are not accurately modelled. In the next section, the available CFD methods and their advantages with different types of flow problem will be explained.

\subsection{Numerical Methods}

Most of the aerodynamic flows are considered and encountered turbulent flows. The most popular available solver methods to simulate these flows are Reynolds-averaged Navier Stokes (RANS), Large-Eddy Simulations (LES) and Direct Numerical Simulation (DNS) method to perform simulations.

The widely used numerical method nowadays is the RANS method. In RANS, all turbulence scales are modeled and only the mean flow properties are calculated directly. The coarser grids can be utilize in the RANS method compared to the other two methods, hence less computing resources are needed. RANS method has been accepted as a general purpose numerical tool by many researchers. However, the selection of turbulence model must be taken care of since the models tend to developed and calibrated for specific application.

LES is a good compromise between the expensive DNS and less accurate in RANS procedures. When the large eddies are resolved, the smallest sub-grid-scale eddies are modeled. Based on the underlying physics that the largest eddies, directly affected by the freestream boundary condition, that carry most of the Reynolds stresses and must be resolved directly. Meanwhile small eddy is independent of the 
freestream condition and can be accurately solved through modelling. LES also required highly accurate spatial and temporal discretization. Therefore to solve the mean flow properties together with the large scales of turbulence may still provide result with the same quality as the DNS method. This method also required large computing resources and therefore is still not being used as a general purpose tool.

DNS is the most forward approach to the solution of turbulent flows. In other words, DNS directly simulated all the flow scales, from largest to the smallest scales of turbulent fluctuation. The governing equations are discretized and solved by accurate and higher order numerical schemes and extremely fine grids. The mesh should be fine enough to resolve the smallest scale of motion. DNS obtain accurate three dimensional, time-dependent solutions of the governing equations completely free of modeling assumption. But DNS has limitation. It use higher order numerical schemes which is difficult to construct and come with larger computational overhead. It also required a large number of grid point to resolve the turbulent scales correctly. A very large and powerful computer is required to achieve this simulation.

\subsection{Problem Statement}

Over the past several decades, numerous experimental and numerical investigations have been carried out to develop an effective flow control system over single airfoils. It was found that airjet (synthetic jet and pulsed jets) [3] was more effective in drag reduction and lift enhancement when compared to steady blowing [4]. In case of deployable vortex generator, it led to the elimination separation zone over the static vortex generator [5].

Wing need to generate enormous amount of lift force in order to reduce the ground speed and runaway length during take-off and landing. A complex and 
heavy, multi-element high-lift device is already being employed in modern commercial aircraft. The two-element high-lift devices such as flaps can be applied only when flow separation on the flap at high flap angles can be controlled. Experimental investigations by Petz and Nistche [6] have shown that massive flow separation can be reduced by blowing jet near the flap leading edge. Osborn [7] stated that the deployable vortex generator on the flap leading edge is very effective to enhance the momentum mixing and energizing the boundary layer which helps delay the flow separation.

Generally, active flow control device such as airjets and MEMS are very complex and expensive and therefore needs more utilization of mechanical system. In the present study, the author offers a much simple device which uses a single mechanism system hidden inside the wing during cruise condition. This current study is motivated by the lack of numerical work using movable vortex generator on the wing's flap.

In addition to that, numerical works is more fast, cheap and simple to utilize compared to the experimental work. Previously, Ahmad [8] conducted this numerical works of oscillating SBVG on diffuser. The current work will be focused on the oscillating vortex generator and the response of the flowfield over a wing's flap for the development of the high performance aircraft. 


\subsection{Aims and Objectives}

The aim of the current study is to perform a numerical investigation on the performance of oscillating SBVG on a wing's flap. The objectives are as follow:

- To analyze the interaction between a turbulent boundary layer and embedded longitudinal vortices produced by oscillating vortex generator

- To simulate interaction between turbulent boundary layer and unsteady vortices induced by oscillating SBVG on wing's flap

- To investigate the parameter involved in this flow interaction such as reduced frequency and oscillation amplitude.

\subsection{Thesis Organisation}

This thesis consists of six chapters. An introduction is presented in Chapter One which provides the introduction of flow control, problem statement and the objectives of the project. Chapter Two presents the literature review. This section will include the discussion of types of active vortex generators devices and numerical studies. Chapter Three consists of methodology used for the simulation of current work. The details of computational methods used to model an oscillating SBVG on a flat plate are described. Chapter Four discussed the results from the CFD simulation of the oscillating SBVG on a flat plate. The oscillating SBVG has been applied on Eagle 150B wing's flap, the setting and results are presented in Chapter Five. Finally, conclusions and future work are stated in Chapter Six. 


\section{CHAPTER 2}

\section{LITERATURE REVIEW}

In this chapter, a brief review of the previous works related to the current study is presented. Studies pertaining to flow separation control, types of active flow control devices, pre-processing and solver setting for numerical investigation of the active flow control devices are also included. The conclusion from these studies is discussed in the last section of this chapter.

\subsection{Flow Separation Control}

Basically, the flow separation control devices are used to postpone flow separation so that form drag is reduced, stall is delayed, lift is enhanced, and pressure recovery is improved. The utilization of flow separation control devices are prominently used in the performance of space, land and marines, heat exchanger [9], turbo- machineries [10], and a variety of other technologically important systems involving fluid flow. The advantages of separation control includes effective lowReynolds-number airfoils [11-13]; increased $C_{L \max }$ for increased payload [14, 15]; reduced drag missiles, automobile, ship and helicopter [16, 17]; supermaneuverability; efficient and effective stall or spin control [18-22]; and numerous other applications in fluid dynamics. For example, an increase of $46 \%$ in the aircraft maximum lift coefficient results in a larger payload for a fixed approach speed [2325]. Similarly, an increase in the take-off lift-to-drag ratio (L/D) results in a larger payload or a longer range. Also, a gain in the lift coefficient at a constant angle of attack reduces the approach attitude, allowing for a shortened landing gear with a corresponding reduction in aircraft weight [26]. On the civil transport, this separation 
control devices also correspond to the total drag reduction over $11 \%$ accompanied with $6 \%$ to $10 \%$ reduction in fuel consumption [27-29]. Moreover, by using MicroElectro-Mechanical-Devices (MEMs), the high shear-stress streaks within the boundary layer reduce over $8 \%$ of local skin friction $[28,30]$.

\subsection{Types of Active Vortex Generators}

Active flow control techniques require energy expenditure, to manipulate fluid flow. Several studies have been carried out such as the air jet vortex generators [4, 31-51], movable vortex generators [7, 52-59], and plasma actuator [60-66]. Air jet vortex generators could be steady or pulsed jet. Airjet devices are based on active blowing in form of jets from the wall and have skewed and pitch angles to the freestream; mechanical systems is used to generate motion for vortex generator that can be tuned parallel to boundary layer while plasma actuator used dielectric materials and voltage to modify the velocity. All the techniques are used to induce large coherent vertical structure that convects downstream and introduces high momentum into the boundary layer. Active flow control (AFC) have been focused mainly on two areas namely, air jets $[4,31-51]$ and structural vibration $[7,52-59,60$ 66]. A brief explanation of these two categories is presented in the following subsections.

\subsubsection{Air Jets}

\subsection{1(a) Synthetic Jets}

One successful and popular actuator in this new decade is the zero-net-massflux (ZNMF) which used a membrane in a small cavity and produce blowing and suction known as "Synthetic Jets"[ 4, 31-51]. This small device of synthetic jet actuator is made-up by a cavity with a movable membrane connected to an orifice. 
The movable membrane is capable of modifying the flow in the cavity of the synthetic jet actuator, and influences the boundary layer. In some of these experiments [4, 31-51], a small slot across the entire span connected to a cavity inside the airfoil is employed to produce oscillatory synthetic jets.

A synthetic jet simulation has been performed by several researchers $[4,31-$ 34] on the airfoil at low Reynolds number, considering the airfoil chord length, freestream velocity and the angles of attack from $10^{\circ}$ to $20^{\circ}$ (see Figure 2.1 ). For each angle of attack, the velocity amplitude, the frequency and the angle with reference to the wall were optimized to increase the time averaged lift. Simulation results have been compared with the experimental data, and qualitative and quantitative agreement has been obtained for both uncontrolled and controlled cases in terms of mean pressure coefficient and streamwise velocity profiles. The results showed that the surface suction could increase the lift coefficient; the injection resulted in decreasing the skin friction [4]. The synthetic jet device was identified as the most effective in terms of drag reduction and less power requirement. The main reason for reduction in drag was the removal of the low momentum fluid by the jet during the suction of the cycle followed by energizing of the flow during the blowing phase. It also confirms that synthetic jet actuation effectively delays the onset of flow separation and causes a significant increase in the lift coefficient. 


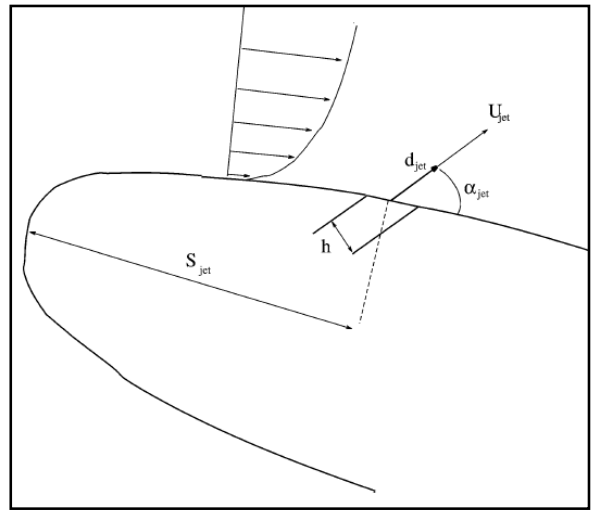

(a)

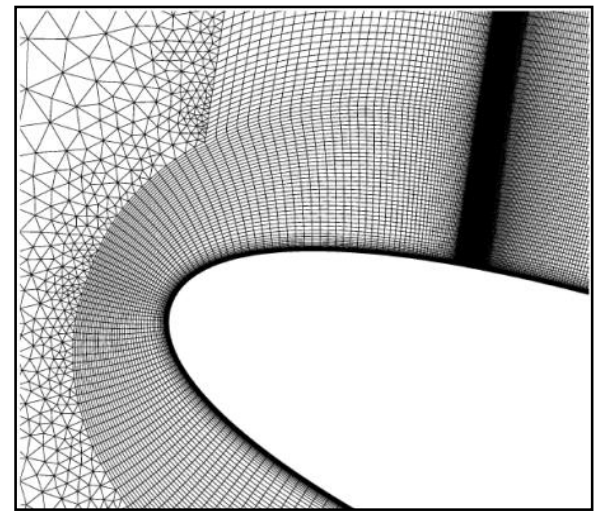

(b)

Figure 2.1: (a) Diagram of synthetic jets on NACA0015; (b) Mesh close to jet [31]

The utilization concept of AFC has been applied to the aerodynamic flow configuration in order to delay the separation of the flow and to increase the lift [3043]. The periodic blowing and suction [33] and co-flow jet (CFJ) [34] effectively reduce the massive separation at the flap (see Figure 2.2). This CFJ inject a high energy near the leading edge tangentially and the same amount of mass flow was sucked away near the trailing edge. At low angle of attack with moderate jet coefficient, the co-flow jet airfoil would not only enhance the lift, but also reduce the drag or even generate the negative drag (thrust). The co-flow jet could control the pressure drag by filling the wake and generate negative pressure greater than the friction drag, which allows the aircraft to cruise with very high aerodynamic efficiency. At high angle of attack, both lift and the drag were higher compared to the airfoil with no flow control, which might enhance the performance of take-off or landing within short distance. 


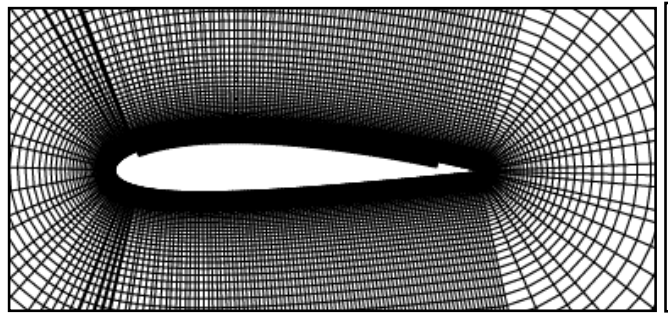

(a)

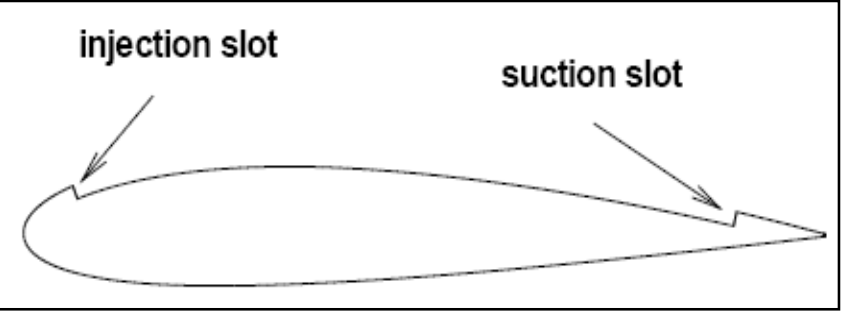

(b)

Figure 2.2: (a) Mesh around the airfoil with co-flow slot; (b) Baseline airfoil NACA2415 with co-flow jet slot [34]

Another blowing jet study applied on a flap was conducted by Petz and Nitsche [6] and Rhee et al [35]. The aim was to enhance the aerodynamic quality of the complete configuration by suppressing the flow separation on the flap as a result of the severe adverse pressure gradient. The flow was excited using a pulsed wall jet emanated from the upper surface near the flap's leading edge through a small spanwise-oriented slot (see Figure 2.3). The massive flow separation at large deflection angles was prevented, increasing the flap deflection angle by up to $10^{\circ}$. The lift was increased by up to $12 \%$ while the drag was reduced by the same amount. This enhanced the lift-to-drag ratio by $20-25 \%$. The overall maximum lift was improved by as much as 5\% [6]. CFD studies carried out by Rhee at al [35] has shown that this device is more efficient at smaller angle of attack $(\alpha)$ and momentum coefficient $\left(C_{\mu}\right)$ especially for low-speed maneuvering. 


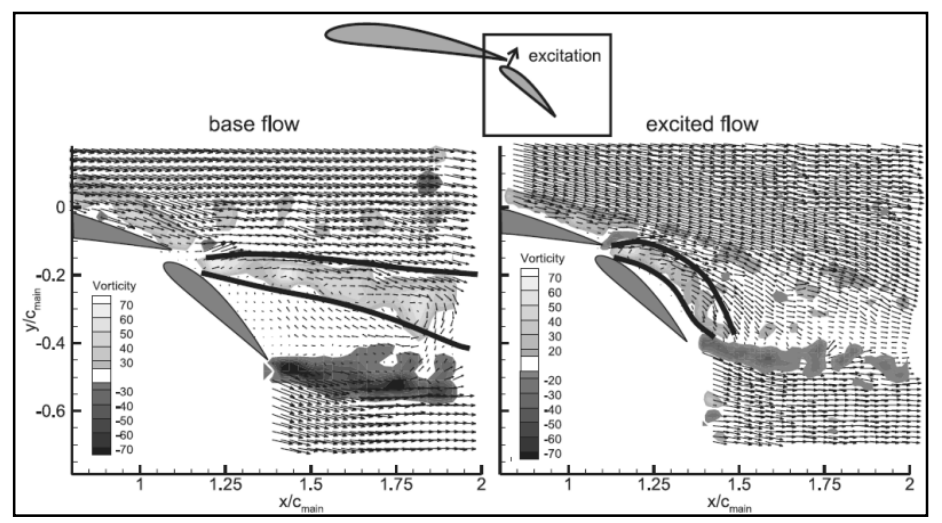

Figure 2.3: Data for an unexcited and excited flow [6]

The capability of synthetic jet from microactuators to interact within the turbulent boundary layer for a complex actuator cycle has been demonstrated numerically by Kitsios et al [36], Iaccarino et al [37],Lin et al [38], Weiqi et al [39], Mello et al [40], and Monokrousos et al [41](see Figure 2.4). The motion of movable membrane plate was treated as the moving boundary by prescribing the displacement on the plate surface $[36-38,40]$. The simulation result illustrated the time evolution of the substantial vertical structure originating from the jet orifice and its successive interaction with the crossflow to change the flow structure inside the boundary layer during discharge stage. In the suction stage, the vertical velocity was continually reduced, causing shrinkage and eventually collapse the counter rotating vortex pairs [38]. 


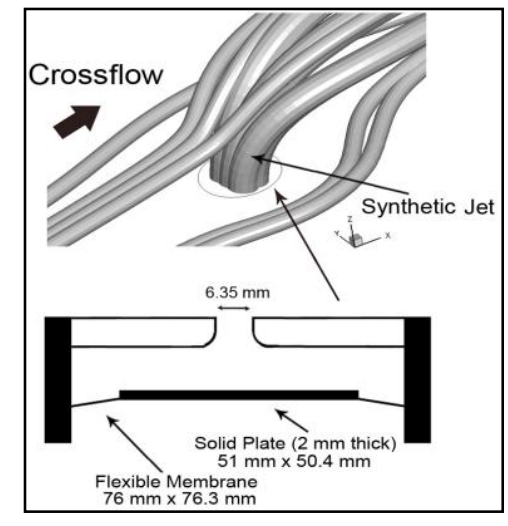

(a)

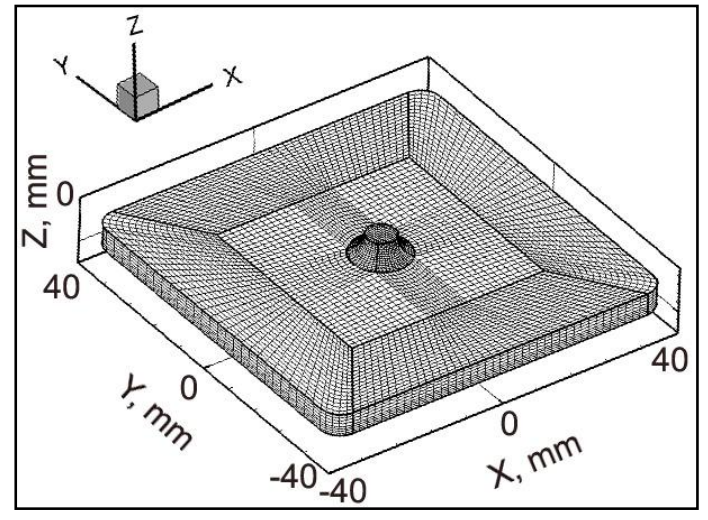

(b)

Figure 2.4: (a) Diagrams of a Synthetic Jet Actuator (SJA) in crossflow;

(b) Numerical grids of SJA [38]

Synthetic jet also contributed to an increase of streamwise velocity component $\partial u / \partial y$ near the wall (see Figure 2.5). Mello et al [40] had carried out numerical study of synthetic jet actuators on the flow of the boundary layer developed on a flat plate and hypothetical airfoil. Three parameters namely slot length (d), frequency ( $\omega$ ) and amplitude (A) of the synthetic jet are used to delay the fluid flow separation. The results with different parametric studies were inspected through a temporal Fourier analysis. The performance of the synthetic jets provided an increase in the value of $\partial u / \partial y$ which was more than the double the value in relation to the flow profile without the synthetic jet. The flow oscillation introduced by the synthetic jet caused acceleration of the flow close to the surface of the flat plate. The increase of $\partial u / \partial y$ in the case of airfoil was higher when compared to the result obtained in the flow simulations on a flat plate. The idea of the synthetic jet is to avoid separation and increase $\partial u / \partial y$ near the wall. 


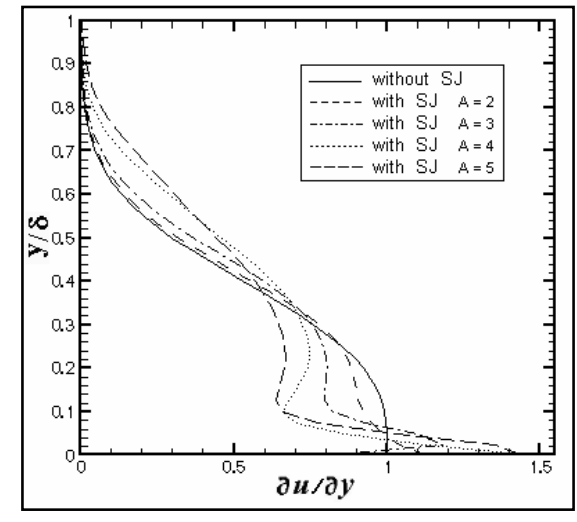

(a)

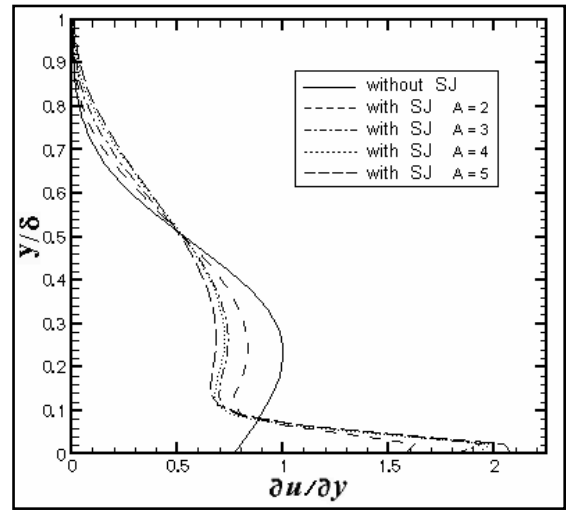

(b)

Figure 2.5: Temporal Fourier analysis with variation of oscillation amplitude for

$$
\omega=17 \text { and } \mathrm{d}=0.225 \text { for (a) flat plate; (b) airfoil [40] }
$$

Jet and Vortex Actuators (JaVA) are zero-net mass flux systems which provide negligible drag when the system is not actuated yet requires no external plumbing, allows reduced vehicle mass and design simplicity. Compared with other zero-net mass flux system, synthetic jet uses the interaction with an external flow to generate vorticity. According to Lachowicz et al [42], JaVA does not rely on external flow to generate vorticity and generate over a range of amplitudes and frequencies, potentially allowing control over different flight regimes. The JaVA consists of a cavity with a lightweight rigid body which serves as the actuation surface. The plate is oscillated in the vertical direction such that the plate motion is uniform along its length and width and driven using a mechanical oscillator as shown in Figure 2.6(a). The plate acts like a piston pumping air out of the cavity on the down-stroke and sucking air into the cavity on the upstroke. This system will generate a helical vortex that has potential in delaying separation by energizing the boundary layer on wing surface with high-momentum fluid from the outer boundary layer. 
Computational simulation of JaVA has been performed by Kandil et al [43] (see Figure 2.6(b)). The computed results showed good agreement with the experimental data.

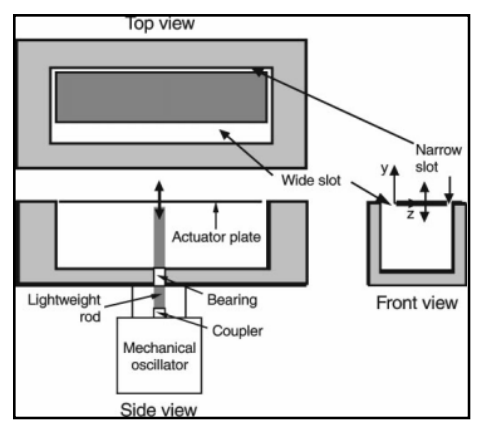

(a)

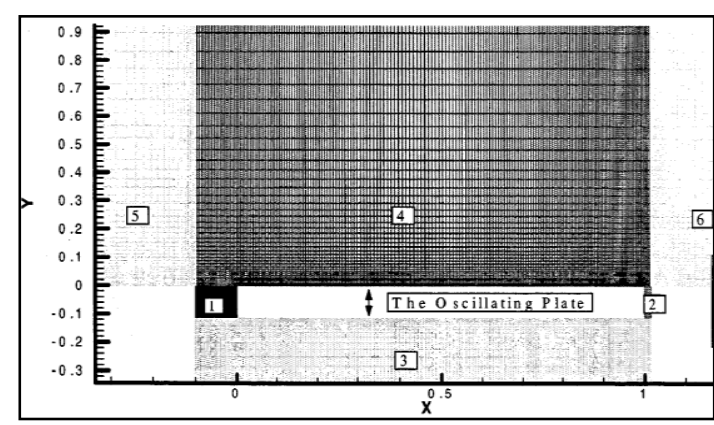

(b)

Figure 2.6: (a) JaVA Actuator [42]; (b) Multi-block grid [43]

\subsection{1(b) Pulsed Jets}

Some investigators namely Sun and Sheikh [44], Coiro et al [45], Vadillo et al [46], Deng et al [47], Ekaterinaris et al [48], Yueping Guo [49], Tilmann et al [50] and Magill et al [51] used different techniques of blowing. They used both steady and unsteady-blowing technique as tools for turbulent separation control which was applied on airfoil surface. This pulsed blowing jet depends on four parameters namely reduced frequency $(k)$, momentum coefficient $\left(C_{\mu}\right)$, chord Reynolds number $\left(\operatorname{Re}_{c}\right)$ and the velocity ratio (VR). The numerical simulation of a pulsed-blowing system was conducted to highlight how aerodynamic performance depended on geometrical parameters to drive the design of the experimental test (see Figure 2.7). The results showed that this technique was very effective to delay or suppress separation on a single component airfoil in the prestall area, focusing on cruising conditions [44]. They also found that the length of separation bubble was 
reduced (almost removed) after unsteady blowing was applied. Pitching and skewing angle also obtained the best efficiency based on the increase of lift over drag and decrease of blowing mass flow.

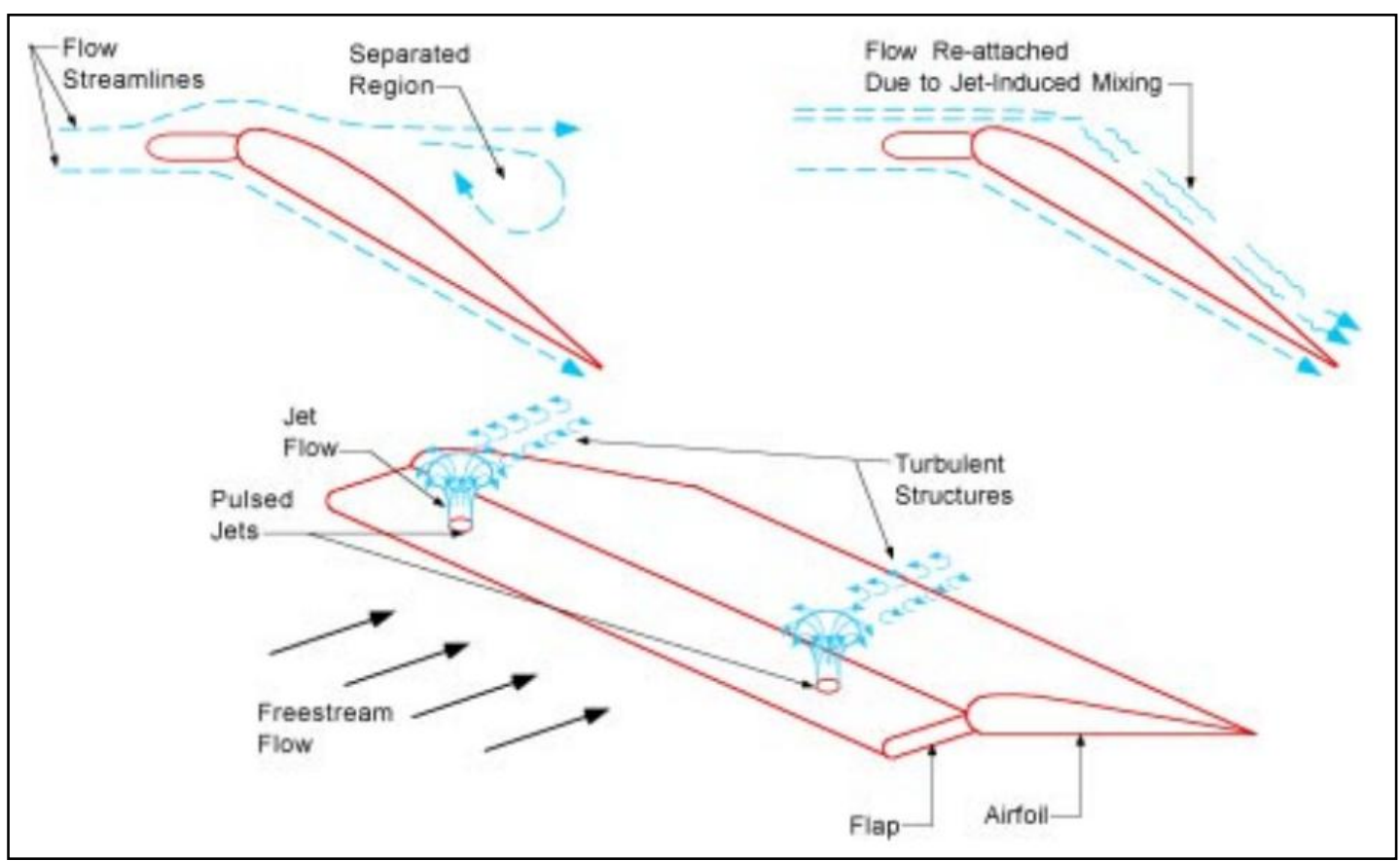

Figure 2.7: Schematic of pulsed vortex generators jet flow control on the flap surface [51]

The effectiveness of pulsed vortex generator jets (PVGJ) is quantified based on its path, strength, persistence of the generated vortices and their influence in the boundary layer and was examined experimentally and numerically by Tillman et al [50] (see Figure 2.8). Blow harder (at higher velocity) or modulate (pulse) the flow are the two methods to increase the power of the steady jets. Results showed the path of the primary vortices appears to be primarily a function of the maximum pulse velocity, or the velocity ratio. Blow too little of jet velocity gives an appreciable effect, but if too high, the vortices will be force out of the boundary layer, resulting in great losses in effectiveness. Persistence in the circulation requires vortex to 
remain in the boundary layer. If the vortex pulses leave the confines of the boundary layer, they are quickly overcome by the freestream momentum and dissipated. A function of the time-average mass flow rate is essentially depends on strength of the primary vortex. The effective way to produce persistent vortices while greatly reduces mass flow by using pulsing. Pulsing jet at $50 \%$ duty cycle resulted twice the mean circulation in the primary vortex as steady blowing at the same average mass flow rate. When the duty cycle was reduced to $25 \%$ at the same pulse velocity, the primary vortex still stronger than the steady jet, was more persistent, and required half the mass flow rate.

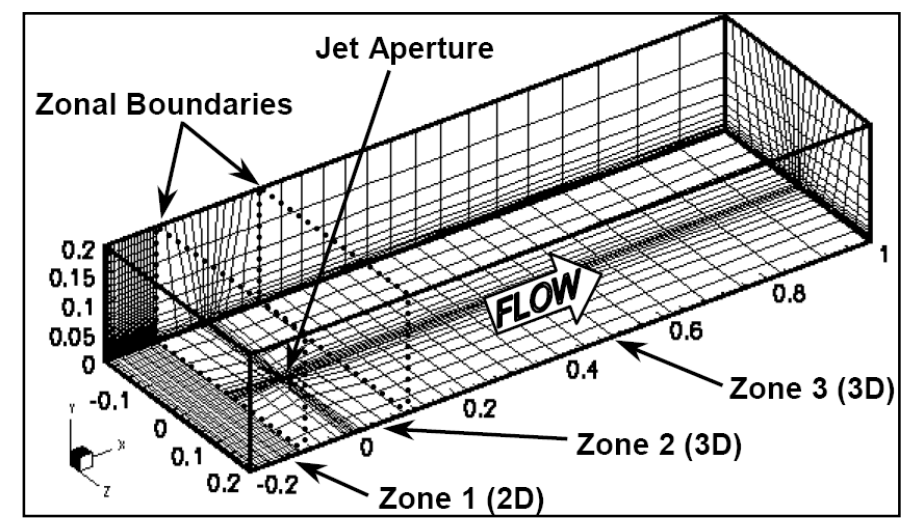

Figure 2.8: Grid features for numerical simulations [50] 


\subsubsection{Structural Vibrations}

Another type of active flow control device was structural vibrations. Some examples are movable vortex generator [5,7,52-55], trailing edge deflector and vortex generator [56], self-activated movable flap [57], miniature trailing edge effectors [58,59], and plasma actuator [60-65]. Normally, these devices use mechanical system to generate periodic vortices. Most of the researchers used a test bed that has an adverse pressure gradient effect such as airfoil. For example, an experimental work by Osborn et al [7] found that high frequency deployable micro vortex generator system (HiMVG) oscillated between 30 to $70 \mathrm{~Hz}$ was very effective in mitigating flow separation on the upper surface of a deflected flap. Then, an ideal technique in numerical simulation of the time-dependent response of boundary-layer flow to active vortex generator (AVG) is immersed boundary method was investigated by Shan [5]. These vortex generators are used to generate streamwise vortices which are transported to downstream and affect the boundary-layer flow in control region (see Figure 2.9(a)). The AVG can be deployed and retracted from the surface of the flat plate with the pitch ranging from $0^{0}$ to $30.96^{0}$. In numerical approach, it shown that the discrete direct forcing is very effective with curvilinear mesh combination. Subsequently, these works was carried out on a NACA 0012 airfoil [52] (refer Figure 2.9(b)). They found that this new type of device is able to suppress flow separation. Both passive and active vortex generators were investigated. The results showed that passive vortex generator can eliminate the separation by reattaching the separated shear layer and reduce the size of the separation zone by more than $80 \%$. The active vortex generators are more effective because the separation is not visible in the mean flow. The flow behind the AVG was 
compared to the experimental data. A fairly close agreement was obtained in between the experiment and numerical methods.

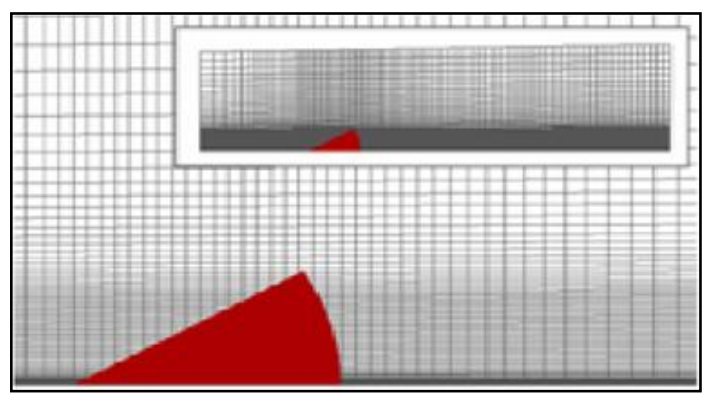

(a)

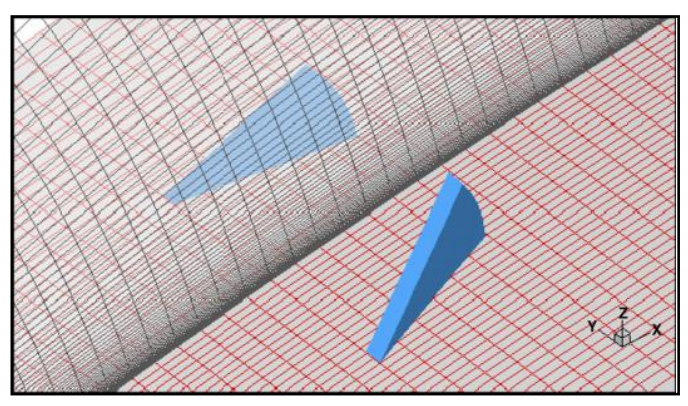

(b)

Figure 2.9: Grids in computational domain on the (a) flat plate [51]; (b) upper surface of the airfoil and in $\mathrm{x}-\mathrm{z}$ plane [52]

Another model that has an adverse pressure gradient is a diffuser ramp. Ahmad et al [53] used oscillated vortex generator in a simple harmonic motion in the range of $0^{0}$ to $15^{0}$ where the frequency corresponded to the frequency of the largest eddies in the boundary layer. This preliminary result showed that frequency of rotation was to suppress the flow separation. Hattori et al [54] studied the effect of the vortex configurations on phase averaged circulation to examine strength of vortex pairs and development of the vortex core region on zero pressure gradient test bed. They also paid attention on the production of the Reynolds shear stress $(-\overline{u v}$, $-\overline{u w})$. The VG was oscillated in the range of $18^{0}$ to $-18^{0}$ using two stepping motors. In this paper, the vortices interaction between common-flow-up, common-flowdown, co-rotating and single VG had been described.

In transonic conditions of a civil aircraft, the shock wave/turbulent boundary layer interaction and the flow separation on the upper wing surfaces induce flow instabilities, "buffet" and then structural vibration, "buffeting". Buffeting greatly 
affects aerodynamic behaviour and it appears when the aircraft Mach number or angle of attack increases. To overcome this problems, Caruana et al [56] installed the vortex generator (VG) upstream of the shock location and Trailing Edge Deflector (TED) at the trailing edge of the wing (refer Figure 2.10). TED is an active actuators be driven by dynamic movements up to $250 \mathrm{~Hz}$. TED increased the wing's aerodynamics and delayed the onset of buffet. The separated flows were greatly reduced using VG and the buffet was totally controlled even for strong instabilities.

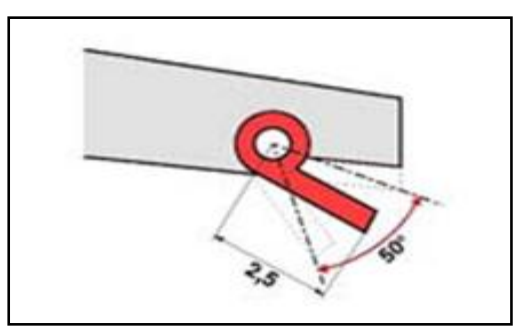

(a)

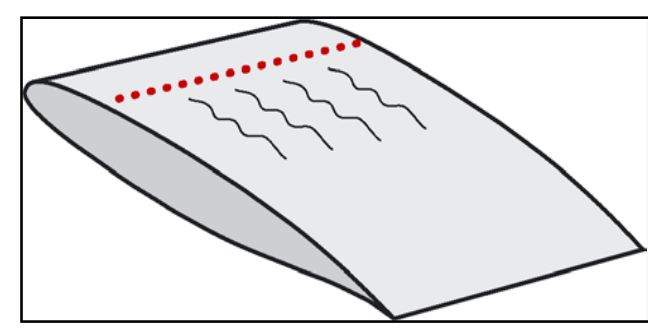

(b)

Figure 2.10: (a) Trailing edge deflector (TED); (b) vortex generator [56]

New types of AFC method using self-activated movable flap to provide the flow physic on airfoil (see Figure 2.11) has been investigated by Meyer et al [57]. The self-adjusting flap is closed at low angle of attack and pops up automatically at higher angle. This simple and cost-effective flow control tool resulted in lift enhancement more than $10 \%$. The blockage of the reverse flow of the flap from the trailing edge region to the suction peak is the main effect in a delayed flow separation. 


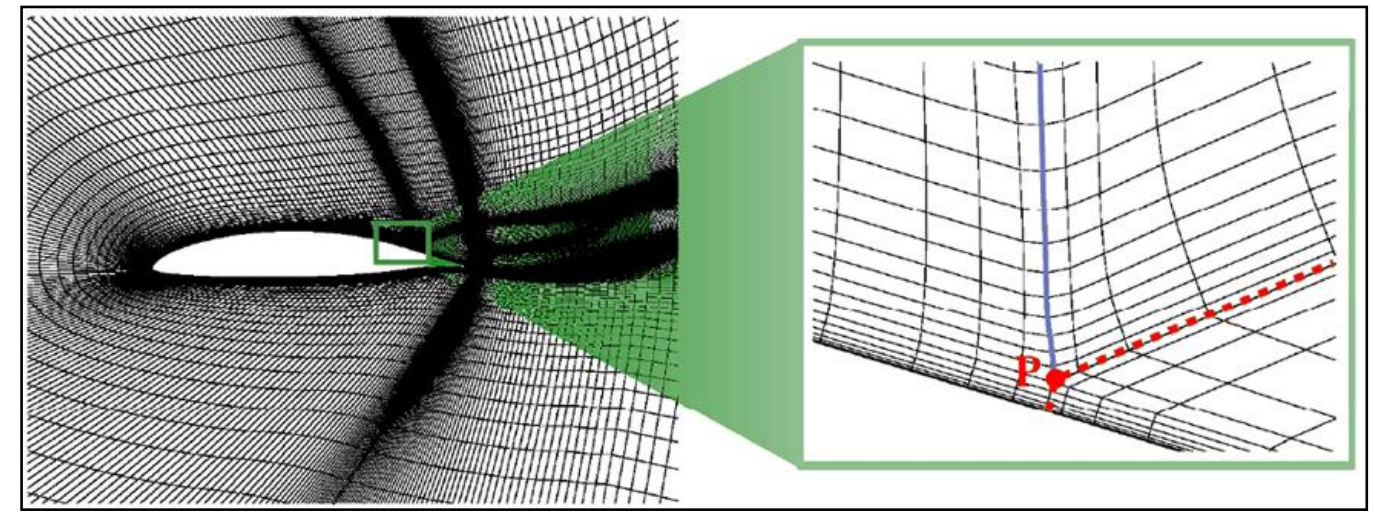

Figure 2.11: Computational mesh that represents the clean HQ17 airfoil as well as a configuration of airfoil and flap [57]

Miniature trailing edge effectors (MiTEs) are small flap (typically $1 \%$ to $5 \%$ chord) actuated with deflection angles of up to $90^{\circ}$. The flap was attached at the sharp and blunt trailing edge airfoils was investigated by Lee and Kroo [58,59]. The sliding rectangular plate behind the trailing edge is to store a flap (see Figure 2.12). Time history of lift and moment coefficient is then computed with the flap sliding up and down in a harmonic motion over a range of frequencies. Steady state computations show that the lift increases as the flap height increase, but the efficiency decrease. The experimental result showed drag reduction of as much as $28 \%$. On the contrary the drag reduction obtained from the computational is less than $5 \%$. Then, the frequency response where used to present the dynamics of the miniature flap. At high reduced frequency, the vortex shedding is clearly observed when the flap is up or down position where the velocity of the flap is close to zero. This device is the guideline in designing vibration control system. 


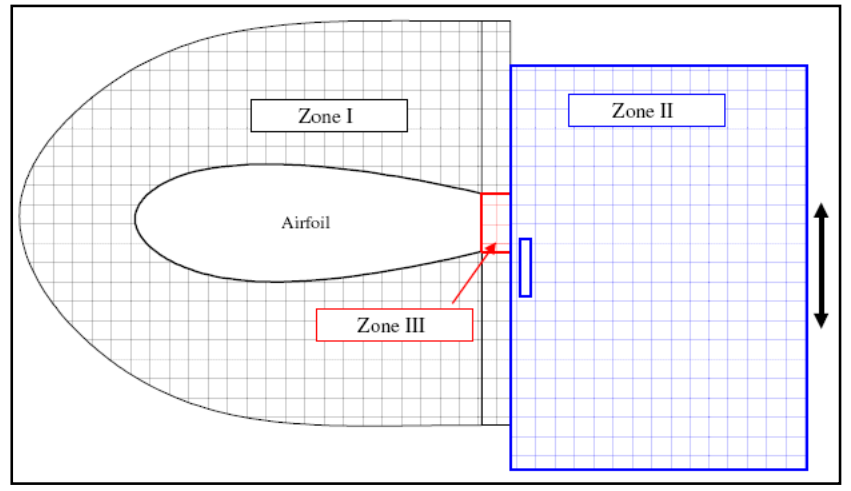

(a)

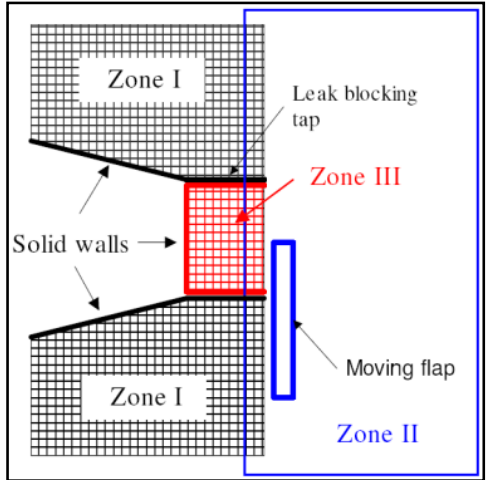

(b)

Figure 2.12: (a) Three zone overset grid used for moving flap computation;

(b) Enlarged view of the overset grid near the trailing edge [58]

Another study was performed experimentally by Jolibois et al [60] on airfoil and numerically by [61-65] using dielectric barrier discharge (DBD) plasma tangentially to the wall, in order to modify velocity in the boundary layer (see Figure 2.13). This type of action was able to fully reattach an airflow naturally separated, for angles of incidence up to $17^{0}$. Moreover, it was clear that the electrical power consumption could be highly reduced while acting close to the separation point, and by using a non-stationary actuation with minimum duty cycle.

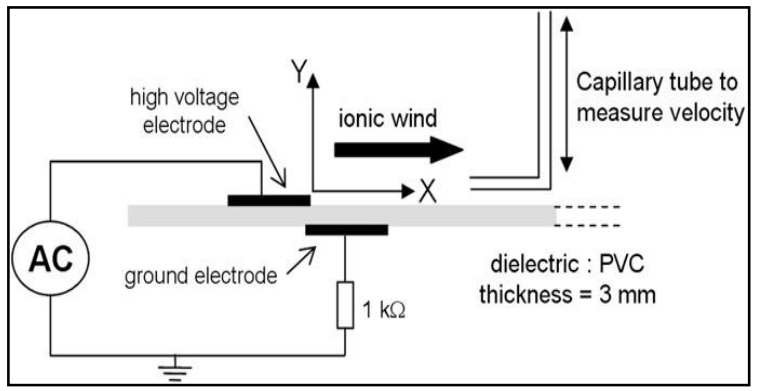

(a)

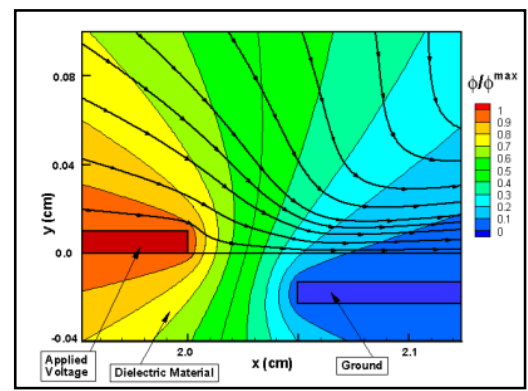

(b)

Figure 2.13: (a) Schematic side view of a single DBD actuator with probes [60];

(b) Computed electric contours and streamlines of the electrodes [63, 64] 


\subsection{Numerical setting and configurations}

In pre-processing stage, there are two types of grid system available including structured and unstructured. Structured grid is the grid to generate and allows convenient construction of high order discretization schemes at interior points. But, it causes a greater complexity and possibly loss of accuracy in the treatment of boundary condition at curved surface. Unstructured grids have the advantage of the lack restriction on where points can be placed. This freedom allows a high degree of automation of generation and sub division of cells which is required for increased accuracy [68-70].

However, the computational time and cost for unstructured mesh computations are generally higher than the structured mesh approach. In military aircraft problem which entails large-scale changes in the geometry problem has led to development of Chimera grid system. In Chimera system, structured grids are allowed to overlap, with information being passed between them through interpolation. For store release the grid associated with the store can be allowed to slide over a background grid associated with the aircraft [68].

\subsubsection{Two-dimensional (2D) simulations}

2D simulations were carried out by a number of researchers $[4,6,31-37,40$, $41,44-46,48,49,57-59,65]$. Two main types of mesh that were used structured and hybrid mesh.

\subsection{1(a) Structured Mesh}

Fully structured mesh for 2D used by the investigators consisted of grid cells between 10000 to 50000 for baseline case. The refinement of grid cells increased 
between 50000 to 500000 because of the slots for air jets. The region of the slot for the airjet, which has a step size, is discretized with a high grid density. Almost uniform grid resolution with approximately 80 points was used for the slot [48]. Fine grid resolution was used adjacent to the wall boundaries to resolve the boundarylayer flow [71]. In the direction normal to the airfoil surface, a large number of grid points were used to provide the resolution needed for the high Reynolds number turbulent flow and the interaction of the airjet with the turbulent boundary layer [4, 48]. The computational domain for the upstream airfoil was approximately at 5 chord lengths away from the leading edge of the airfoil. The upper and lower boundaries were about 5 chord length from the solid surface. The outflow boundary was 10 chord lengths downstream of the trailing edge to minimize the disturbing effects $[4,6,31,32,33-35,44-49,57-59]$. To correctly capture the flow behavior, the maximum aspect ratio of the cells near the surface was kept below 100, normally $y^{+} \approx 1$ and the first cell height approximately at $3.26 \times 10^{-6} \mathrm{~m}$.

Vadillo and Agarwal [46] showed that the grid requirement was very sensitive to the flow condition. To maintain $y^{+}<2$, a different computational grid was required for both $\mathrm{M}_{\infty}=0.8$ and 0.9 . For all the computations reported in this paper, the grid refinement study was performed to ensure that the computed solutions are grid-independent. The uncertainty such as size of the computational domain, grid, numerical algorithm and boundary condition in the computed solution was minimized.

The flat plate with synthetic jet actuator used a total of 300 and 200 nodes in the streamwise and wall normal direction respectively and the total mesh was increased to $20 \times 10^{6}$ after grid adaptation. This mesh is reported to have sufficient 
resolution to capture the features of flow fields over the hump utilize by plasma actuator [5, 7, 50-53] and synthetic jet [17].

Meanwhile, Lee and Kroo [58] used 2D structured mesh which is divided into three-zone overset grid for the moving grid computations (see Figure 2.12). These three-zones are called multi faces. Zone I is a C-grid surrounding only the airfoil without the wake. Zone II is a rectangular region downstream of the trailing edge and contains the flap where the grid points on the flap surface are specified as solid wall boundaries and the point inside the flap are blanked out using iblank. Zone III is small rectangular grid needed to define the solid wall for the blunt trailing edge. The interfaces between Zone I and III are solid wall boundaries and these two small taps block the flow between the trailing edge and the flap. Zone II slides up and down as rigid body translation according to the motion of the flap. Grids are generated at each time step as well as the interface file that gives the information for updating the boundaries.

\subsection{1(b) Hybrid Mesh}

The hybrid mesh consists of structured and unstructured grids. The computational mesh obtained by Rhee et al [35] consists of approximately 2 million quadrilateral and triangle cells. The first cell height approximately equal to one in terms of wall $y^{+}$. Circular sub-domain around the hydrofoil is generated and triangular cells fill the remaining region of the sub-domain. The region outside the circular sub-domain is also filled with appropriately growing triangular cells.

In the study carried out by Duvigneau and Visonneau [31], 2D unstructured grid with approximately 90000 cells was used for the calculation. This grid consists of a fine mesh with quadrangular cells close to the wall and the near wake region, in 